\title{
Conjoined lumbosacral nerve roots: observations on three cases and review of the
} literature

\author{
M. Artico; S. Carloia*; M. Piacentini*; G. Ferretti*; M. Dazzi**; S. Franchitto and E. Bronzetti***
}

Department of Human Physiology and Pharmacology V. Erspamer. University La Sapienza. *Addolorata Hospital Division of Radiology, **Service of Neuroradiology and ***Department of Cardiovascular, Respiratory and Morphological Sciences. University La Sapienza. Rome. Italy.

\section{Summary}

Lumbosacral nerve root anomalies are a rare group of congenital anatomical anomalies. Various types of anomalies of the lumbosacral nerve roots have been documented in the available international literature. Generally speaking, these anomalies may consist of a bifid, conjoined structure, of a transverse course or of a characteristic anastomized appearance. Firstly described as an incidental finding during autopsies or surgical procedures performed for lumbar disk herniations and often asymptomatic, lumbosacral nerve root anomalies have been more frequently described in the last years due to the advances made in radiological diagnosis (metrizamide myelography and CT, MRI).

Our study comprised three patients with conjoined lumbosacral nerve roots, representing $0.25 \%$ of a total of 1200 patients who underwent lumbosacral CT/MRI procedures in the Addolorata Hospital and in the Service of Neuroradiology of the University of Rome "La Sapienza" during the last three years (March 2001March 2004). We report our experience with three cases of conjoined lumbosacral nerve roots and analyze the most important literature on this topic.

MR imaging is a better diagnostic procedure (in comparison to $\mathrm{CT}$ ) for the differentiation of nerve root anomalies and, in particular, coronal sections furnish a precise definition of the profile of the conjoined/enlarged rootlets. In fact, the accurate information derived from MRI of multiple planes may be priceless for the preoperative and diagnostic evaluation of lumbosacral nerve root anomalies.

KEY WORDS: Lumbosacral nerve root anomalies. Conjoined nerve roots (CNR). Spine. CT. MRI.

Raices lumbares conjuntas: a proposito de tres casos y revision de la literatura

Recibido:31-01-05. Aceptado. 20-08-05
Resumen

Las anomalías congénitas de los nervios raquídeos lumbares no son muy frecuentes y suelen ser difíciles de detectar en TAC sin contraste. La raíces lumbares pueden ser conjuntas o bífidas $y$ frecuentemente son descubiertas en las autopsias clínicas. Cursan habitualmente con dolor (episodios de lumbalgia y lumbociatalgia) y sin déficit motor ni sensitivo. Las raíces conjuntas frecuentemente se aprecian en la RM.

Presentamos tres casos de raíces lumbares conjuntas intervenidos en el Servicio de Radiología del Hospital Addolorata de Roma y en el Servicio de Neurorradiología del Hospital Universitario de Roma "La Sapienza" entre 2001 y 2004, representando $0.25 \%$ de todos los 1200 pacientes evaluados mediante TAC y $\mathrm{RM}$, y revisamos los aspectos diagnósticos presentados en la literatura mundial.

La RM es, en muchas ocasiones, superior a la TAC simple en el diagnóstico de las anomalías de las raíces nerviosas; además la RM tiene la ventaja de los planos sagitales y coronales.

La visualización de la médula y la cola de caballo, sin necesidad de contraste intratecal, hace que la RM sea el examen ideal para identificar las raíces nerviosas conjuntas, ofreciendo una ventaja clara sobre la TAC.

PALABRAS CLAVE: Anomalías de los nervios raquídeos lumbares. Raíces lumbares conjuntas (RLC). Columna vertebral. Tomografía Computarizada. Resonancia magnética.

Introduction

Numerous reports of lumbosacral nerve root anomalies are described in the literature. These anomalies were assessed on the basis of operative findings, neuroradiologic examination and autoptic studies ${ }^{2-5,7,11,14,16,22}$. Zagnoni in $1949^{26}$

Abreviaturas. CT: Computarized tomography. MRI: Magnetic Resonance Imaging. RM: Resonancia magnética. TAC: Tomografía axial computarizada. 
Table 1

Clinical and radiologic data of the three described cases

\begin{tabular}{|c|c|c|c|}
\hline Sex/Age & Location & Clinical signs/symptoms & CT/MRI findings \\
\hline $\mathrm{M} / 49$ & L5-S1 left & $\begin{array}{l}\text { Lumbar pain, } \\
\text { left lumbociatalgia }\end{array}$ & $\begin{array}{l}\text { Bulging of the L5-S1 } \\
\text { disk; conjoined (double) L5-S1 } \\
\text { rootlets, hypoplasia of the pedicle } \\
\text { and dysmorphic lamina on the left side }\end{array}$ \\
\hline $\mathrm{M} / 65$ & L5-S1 left & $\begin{array}{l}\text { Lumbar pain, } \\
\text { left lumbociatalgia }\end{array}$ & $\begin{array}{l}\text { L5-S1 paramedian disk herniation; } \\
\text { conjoined (double) L5-S1 } \\
\text { rootlets on the left side }\end{array}$ \\
\hline $\mathrm{F} / 38$ & L5-S1 left & $\begin{array}{l}\text { Lumbar pain, } \\
\text { left lumbociatalgia }\end{array}$ & $\begin{array}{l}\text { Schisis of the S1 and S2 laminae; } \\
\text { spondilolysis of L5 on the left side; } \\
\text { conjoined (double) L5-S1 } \\
\text { rootlets on the left side }\end{array}$ \\
\hline
\end{tabular}

was the first to report an anatomical description of an anomalous nerve root. Subsequently Ethelberg and Riishede ${ }^{8}$, Fineschi ${ }^{9}$, Reynolds ${ }^{18}$ and Deyerle and May $^{6}$ described similar cases. In 1962 Cannon et al. ${ }^{3}$ proposed the first classification of nerve root anomalies. Other classifications have been proposed by Postacchini et al. ${ }^{17}$, by Kadish and Simmons ${ }^{11}$ and by Kikuchi et al. ${ }^{12}$.

The percentage incidence of these nerve root anomalies shows a range comprised between 0.3 and $30 \%$, although the last figure may be overestimated. In any case it is probable that anomalies of the lumbosacral nerve roots are more frequent than radiological reports seem to indicate.

The roots most frequently involved by the anomaly are $\mathrm{L} 5$ and $\mathrm{S} 1{ }^{11}$, accounting for $50 \%$ of the total number, while S2 anomalies account approximately for one third of cases; anomalies of other roots are rare. Multiple malformations may be frequent and the majority of them occur on the left side. The diagnosis of these anomalies may be difficult and it is important to develop more sensitive and specific methods for demonstrating them. In fact, a correct diagnostic approach is fundamental in order to avoid errors and to allow a safe and correct surgical approach (if necessary), thus guaranteeing proper management of these disorders. We describe three cases of conjoined lumbosacral nerve roots and discuss the anatomical, neuroradiological and surgical problems in the light of the available literature.

\section{Clinical material and methods}

Our study comprised three patients with conjoined lum- bosacral nerve roots, representing $0.25 \%$ of a total of 1200 patients who underwent lumbosacral CT/MRI procedures in the Addolorata Hospital and in the Service of Neuroradiology of the University of Rome "La Sapienza" during the last three years (March 2001-March 2004). Table 1 summarizes the clinical data of these three patients.

\section{Case 1}

The first patient was a 49-year old man who came to our attention in the Radiological Division of the Addolorata Hospital because of his complaints of mild lower back pain in addition to sciatica. A standard lumbar MRI was performed at a $1.5 \mathrm{~T}$ (Siemens Symphony) machine. Axial and sagittal T1-weighted and gradient echo recalled images were obtained. An hypoplastic pedicle and a dysmorphic lamina on the left side (arrow Fig. 1B) were observed together with a pattern of L5-S1 conjoined rootlets on the same side (Fig. 1A). No surgical therapy was planned and the patient was discharged for a cycle of physiokinesitherapy.

Case 2

The second patient was another 65-year old man who was admitted at the Neuroradiological Service of the University of Rome "La Sapienza" complaining a low back pain associated with left lumbociatalgia. A standard lumbar MRI was performed at a $1.5 \mathrm{~T}$ (Philips) machine. Axial and sagittal T1-weighted SE images were obtained.MRI demonstrated a L5-S1 paramedian disk herniation and conjoined L5-S1 


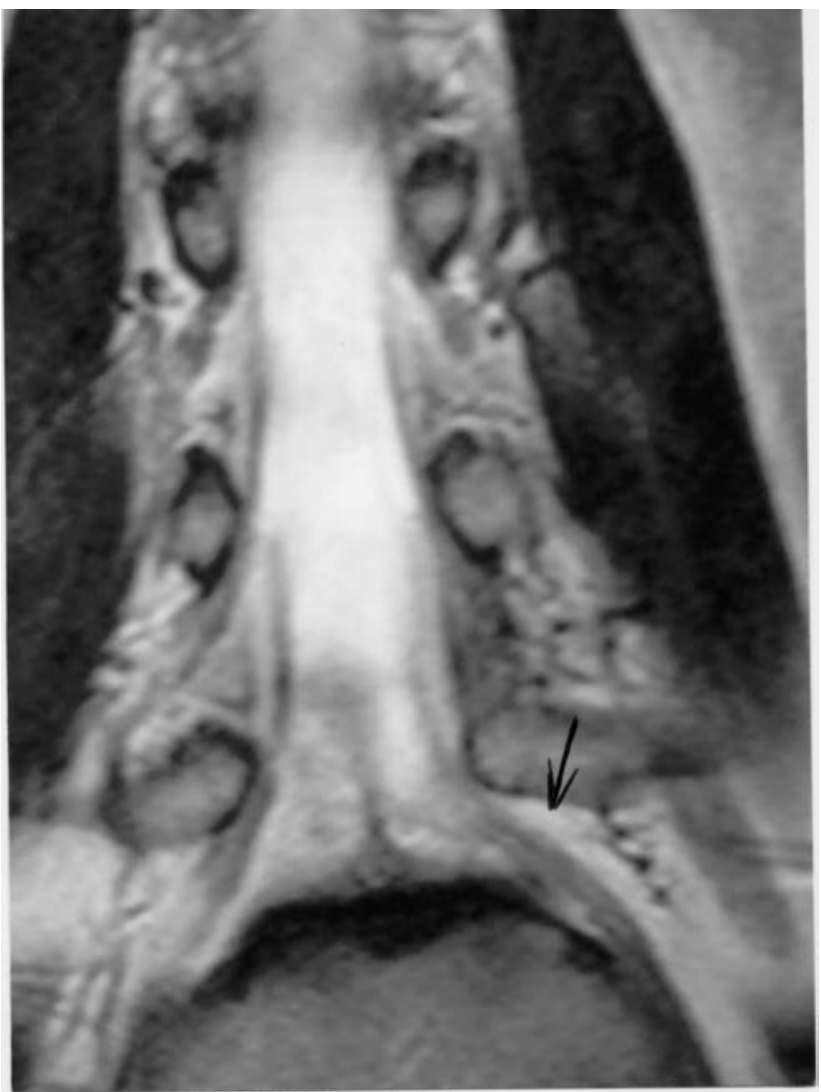

Figure 1 A. Case 1. Coronal MRI section showing the conjoined L5-S1 rootlets on the left side (arrow).

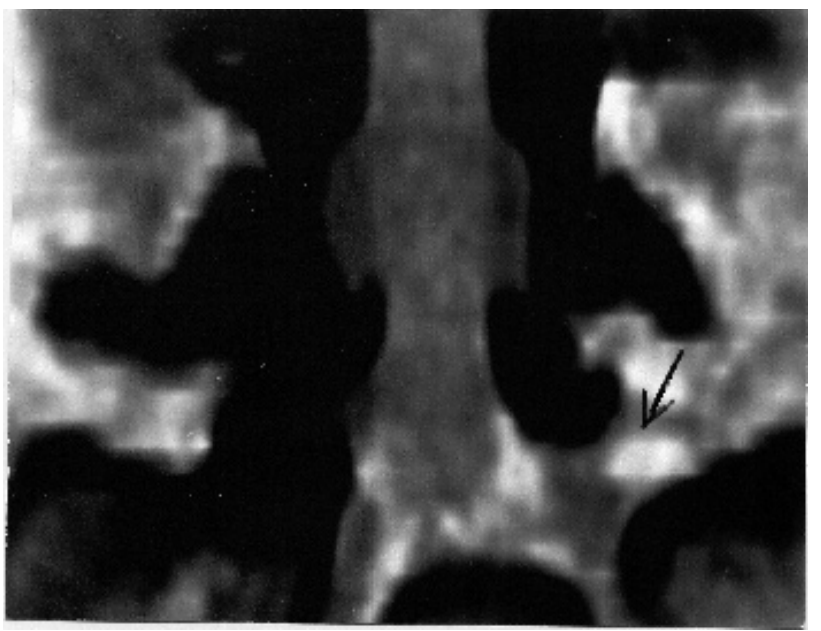

Figure 1 B. Case 1. Coronal CT reconstruction that shows the pedicle hypoplasia and a dysmorphic lamina on the left side (arrow) together with the presence of the conjoined rootlets (L5-S 1 fusion).

rootlets on the left side. Surgical therapy was performed (L5 left hemilaminectomy plus flavectomy) removing the disk herniation and showing the presence of a conjoined origin of L5 and S1 roots on the left. Asymmetry of the radicular sleeves and midway position of the conjoined trunk on the left as compared to the right were observed. The involved sleeve was also broader. Postoperative course was uneventful and the patient was discharged ameliorated in his neurological status on day $7^{\text {th }}$ after operation.

\section{Case 3}

This 38-year-old woman came to our attention in the Radiological Division of the Addolorata Hospital because of his complaints of mild lower back pain in addition to sciatica. A standard lumbar CT was performed with a Toshiba X Vision/Ex machine. Axial and sagittal slices were obtained.

CT and MRI demonstrated a schisis of the S1 and S2 laminae, a spondilolysis of L5 on the left side and conjoined (double) L5-S1 rootlets on the same side (Figs. $2 \mathrm{~A}$, $2 \mathrm{~B}$ and $2 \mathrm{C}$ ). The patient refused further neuroradiological examinations as well as the possibility of a surgical option and was subsequently discharged.

\section{Discussion}

The embryological error causing the lumbosacral nerve root anomalies is unclear. The malformations in which the nerve roots emerge at a more caudal level, or in closely adjacent dural openings, or in a common nerve trunk, probably result from defective migration of the roots during the embryonic development, pending the usual unilateral occurrence of these anomalies. The emergence of roots at a more cranial level and the bilateral anomalies of 1 or more roots are probably due to an abnormal emergence of the affected roots from the spinal cord ${ }^{17}$. Moreover, an abnormal anstomosis between roots may persist either as a band of nerve fibers or as a complete distal union in a common

Table 2

Classification of Cannon et al. (1962)

\section{TYPE Kind of anomaly}

I Conjoined type : 2 roots share a common sleeve that originates from the dura mater

II

Anastomotic type: a normal root bifurcates abnormally after it leaves the dura and branches out to the next caudal nerve

III leaves the dural sac at almost a right angle 


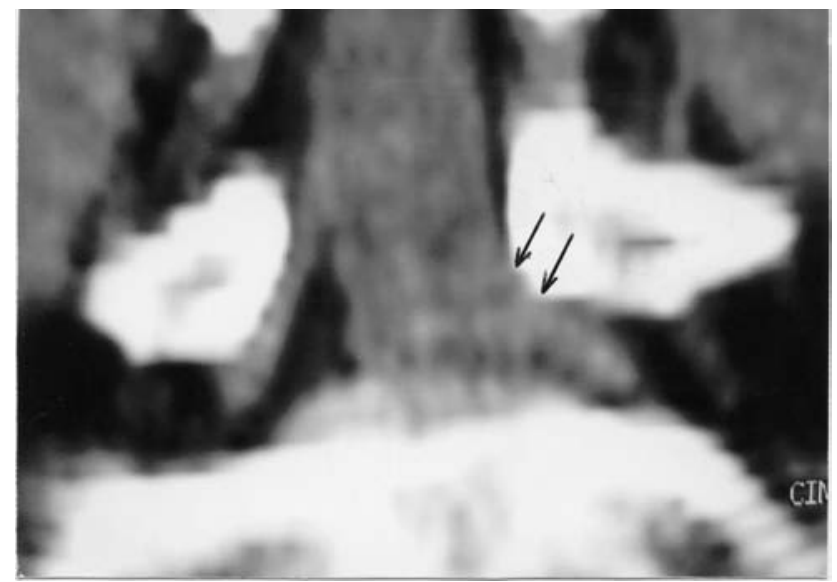

Figure 2 A. Case 3. Coronal CT reconstruction that clearly illustrates the fusion of the rootlets on the left side (arrows).

sheath $^{13}$.

According to Cannon et al. ${ }^{3}$ there are three fundamental types of nerve root anomalies (Table 2):

Type I: conjoined (or confluent) type, in which 2 roots share a common sleeve that originates from the dura mater.

Type II (anastomotic type) in which a normal root bifurcates abnormally after it leaves the dura and branches out to the next caudal nerve.

Type III (transverse type) in which the nerve root leaves the dural sac at almost a right angle.

Postacchini et al. ${ }^{17}$ proposed another classification based on 5 different types (Table 3):

Type I: one or more roots emerge at an abnormal cranial level.

Type II: one root emerges at a more caudal level than normal.

Type III: two or more nerve roots emerge through clo-

\section{Table 3}

Classification of Postacchini et al. (1982)

\section{TYPE Kind of anomaly}

I One or more roots emerge at an abnormal cranial level

II One root emerges at a more caudal level than normal

III Two or more nerve roots emerge through closely adjacent openings of the dura

IV Two nerve roots emerge from the dural sac in a common nerve trunk

V An anastomotic branch connects two nerve roots in their extrathecal course

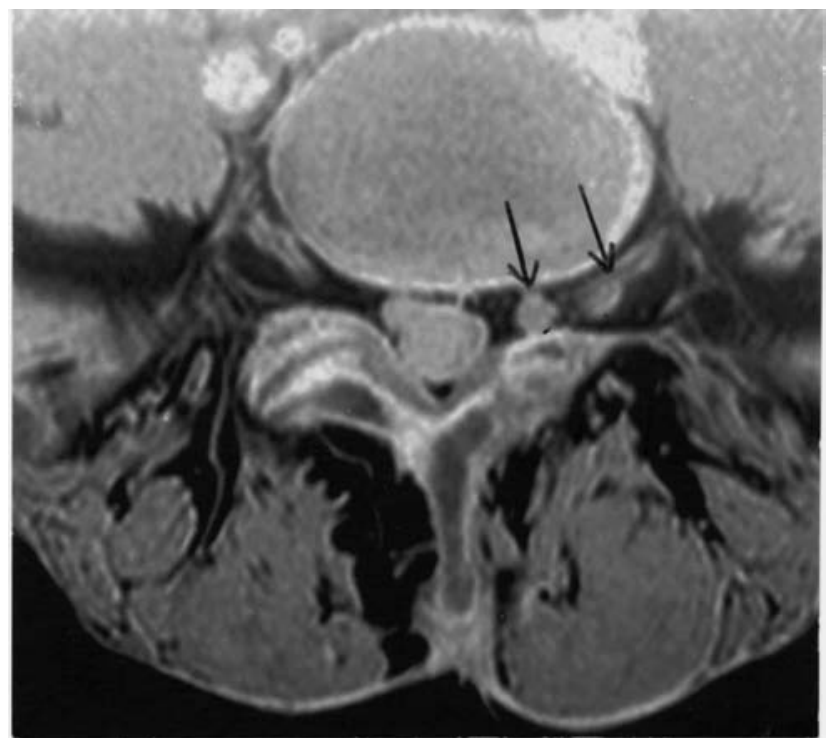

Figure 2 B. Case 3. Axial T1 RM section confirms the enlargement of the foramen and the schisis of S1 lamina together with the presence of two confluent (L5 and S1) rootlets (arrows).

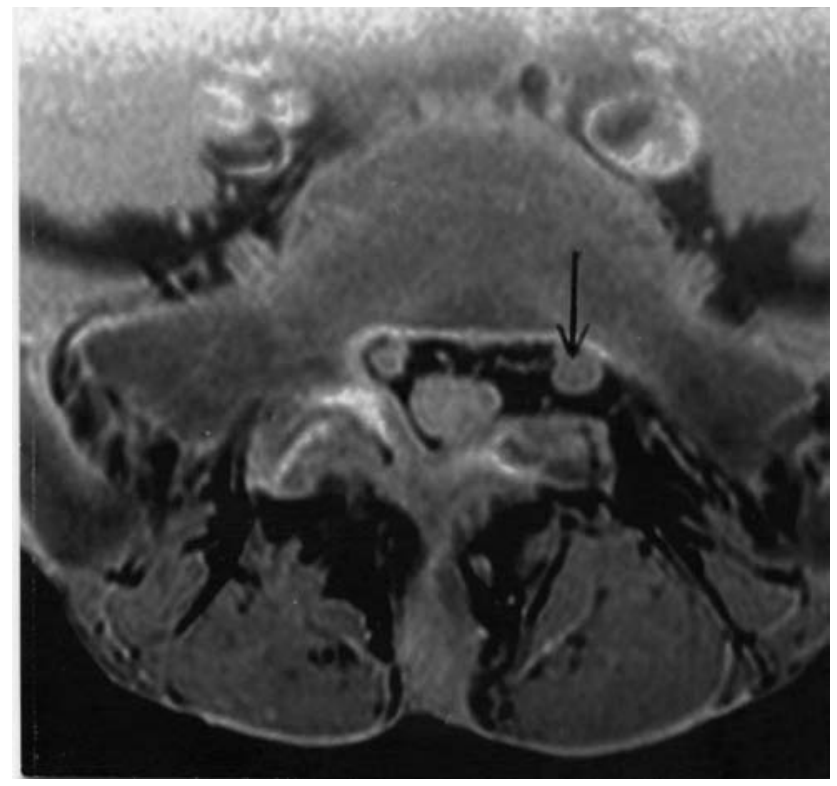

Figure 2 C. Case 3. Axial T1 RM section illustrates the enlargement of the foramen and the fusion, at the level of S1, of the L5 and S1 rootlets in a unique root that appear bigger (arrow) in comparison with the contralateral root.

sely adjacent openings of the dura.

Type IV: two nerve roots emerge from the dural sac in a common nerve trunk.

Type V: an anastomotic branch connects two nerve roots in their extrathecal course.

Kadish and Simmons ${ }^{11}$ classified 4 types of anomalies (Table 4): 
Table 4

Classification of Kadish and Simmons (1984)

\begin{tabular}{cl}
\hline TYPE & Kind of anomaly \\
I & Intradural anastomosis between rootlets \\
II & $\begin{array}{l}\text { Anomalous origin of nerve root, including: } \\
\text { a) cranial origin; b) caudal origin; c) } \\
\text { combination of cranial and caudal origin } \\
\text { affecting more adjacent roots; } d \text { ) conjoined } \\
\text { nerve roots }\end{array}$ \\
III & $\begin{array}{l}\text { Extradural anastomoses between nerve } \\
\text { roots }\end{array}$ \\
IV & Extradural division of the nerve roots \\
\hline
\end{tabular}

Type I: intradural anastomosis between rootlets.

Type II: anomalous origin of nerve root, including: a) cranial origin; b) caudal origin; c) combination of cranial and caudal origin affecting more adjacent roots; d) conjoined nerve roots.

Type III: extradural anastomoses between nerve roots.

Type IV: extradural division of the nerve roots.

The embriology of these root anomalies still remains uncertain. One possible mechanism that may explain an emergence at a more caudal level, in closely adjacent dural openings as well as in a common nerve trunk, postulates a defective migration of the roots during embryonic development. Bilateral anomalies of one or more roots, as well as a more cranial level root emergence, are probably due to an anomalous emergence of the roots involved from the spinal cord. Abnormal anastomosis between roots may be considered as the result of a link due to a band of nerve fibers or of a complete distal union in a common sheath.

From a clinical viewpoint, anomalies and malformations of lumbosacral nerve roots and their coverings usually do not initially produce any symptoms. It is only when further degeneration of disks and/or vertebral joint occurs (often accompanied by stenosing of the spinal canal and of the root canal entrance) that clinically relevant root compressions may be observed. In similar cases, CT doesn't allow a correct evaluation because it often shows a pattern compatible with a disk herniation. Myelography and, especially, MRI are able to demonstrate the right appearance of the anomalies thus permitting a correct planning and management of the different cases. Sometimes MRI may not correctly identify root anomalies due to the similarity of signal intensity between rootlets and epidural veins. In fact, the internal vertebral veins bind laterally at the level of the disk interspace and medially at the level of the pedicles, where they unite via a connecting vein. However, veins may be distinguished from nerve root anomalies (on MR scan) due to the anatomical characteristics of the course and the multiple communications of the internal vertebral veins. In some cases, a spondilolysis or a hypoplastic lumbar pedicle (as in our third case) may be associated with a conjoined nerve root. Bony anomalies (congenital aplastic-hypoplastic lumbar pedicle) may result from the embryological occurrence of a large retrosomatic cleft. When the cleft is of sufficient size it becomes an absent pedicle. If the pedicular defects are relevant, an absent facet and a retroisthmic defect may be observed ${ }^{15,19-21,24,25}$. The presence of nerve root anomalies is often associated with an ipsilateral dysplastic lamina, transverse process and facet thus reproducing a complex anomaly that involves vertebral bone architecture as well as nerve roots. Conjoined nerve roots and an associated enlargement of the lateral recess may be often confused with a dumbbell tumor or a free fragment of an extruded disk on CT scans. MR imaging is a better diagnostic procedure (in comparison to CT) for the differentiation of nerve root anomalies and, in particular, coronal sections furnish a precise definition of the profile of the conjoined/enlarged rootlets (Figure 1 A). In fact, the accurate information derived from MRI of multiple planes may be priceless for the preoperative and diagnostic evaluation of lumbosacral nerve root anomalies. MRI combines the advantages of CT, CT-myelography and classical myelography ${ }^{10}$. Moreover, anomalies of the origin, course, length and diameter of the roots, as well as details of the bone and soft tissues around them, are better visualized by MR imaging ${ }^{10}$.

The operative management of these anomalies depends on the neurological problems and the clinical conditions existing in each individual case ${ }^{13}$. Asymptomatic and accidentally diagnosed cases do not require treatment. Intervertebral disk herniations, associated with root anomalies (with or without bony alterations), have to be treated in order to relieve neurological signs and symptoms. In these cases, an adequate exposure of the roots involved to avoid persistent compression as well as to reduce any traction may be necessary, keeping in mind that a hemilaminectomy with sufficient exposure of the intervertebral foramen or of the lateral recess should be performed to avoid the alterations of stability and to ensure correct mobility of the lumbosacral spine. In fact, in the presence of nerve root anomalies a wide exposure by hemilaminactomy is necessary. It allows an adequate visualization and mobilization of the involved roots, aids in the definition of the conjoined roots and their origin, thus avoiding the risk of laceration and excessive traction $^{13}$. Because a possible concomitant spinal stenosis may be often associated with a herniated disc, unroofing of the lateral recess, foraminotomy and medial facetectomy are necessary to obtain a good decompression and mobilization of the roots. A careful inspection of the disc space 
Conjoined lumbosacral nerve roots: observations on three cases and review of the literature

is always recommended, because a small disc protrusion, which usually causes the radicular symptoms, may be overlooked when the intervertebral space is covered by the anomalous roots ${ }^{13}$. When the abnormal configuration and fixation of the roots (clearly depicted by CT and MRI preoperative studies) prevents an adequate exposure of the disc space on the involved side, the removal of the herniated disc through a contralateral laminotomy may be advisable ${ }^{17}$. A correct surgical treatment of patients with anomalous lumbosacral nerve roots and associated disc herniation or spinal stenosis results in clinical remission or improvement ${ }^{17}$. The relatively high incidence of unsatisfactory postoperative results reported in the literature ${ }^{3,6,8}$ may be often due to some factors, such as previous surgery, accidental opening of the dura or iatrogenic injury to the anomalous nerve roots ${ }^{13}$.

In conclusion, these unusual anomalies may be treated in the same way as other other spinal extradural pathologies as long as correct diagnosis, clinical and prognostic evaluation, surgical planning and management have been carefully performed.

\section{References}

1. Bernini, P.M., Wiesel, S.W., Rothman, R.H.: Metrizamide myelography and the identification of anomalous lumbosacral nerve roots. Report of two cases and review of the literature. J Bone Joint Surg A 1980; 62: 1203-1208.

2. Cail, W.S., Butler, A.B.: Conjoined lumbosacral nerve roots. Diagnosis with metrizamide myelography. Surg Neurol 1983; 20: 113-119.

3. Cannon, B., Hunter, S., Picaza, J.: Nerve-root anomalies in lumbar disc surgery. J Neurosurg 1962; 19: 208-214.

4.Coughlin, J.R., Miller, J.D.: Metrizamide myelography in conjoined lumbosacral nerve roots. J Can Assoc Radiol 1983; 34: 23-25.

5. D'Avella, D., Mingrino, S.: Microsurgical anatomy of lumbosacral spinal roots. J Neurosurg 1979; 51: 819-823.

6. Deyerle, W.M., May, V.R.: Sciatica. Etiology and treatment. Clin Orthop 1954; 4: 166-179.

7. Dragonetti, I.: Anatomical abnormalities of the lumbosacral roots in surgery of compression syndrome due to suspected hernia of the disc. J Arch Orthop 1967; 80: 265-282.

8. Ethelberg, S., Riishede, J.: Malformation of the lumbar spinal roots and sheats in the causation of low backache and sciatica. J Bone Joint Surg B 1952; 34: 442-446.

9. Fineschi, G.: Anomalie anatomiche delle radici lombari. Arch Putti Chir Org Mov 1952; 2: 222-236.

10. Haijiao, W., Koti, M., Smith, F.W., Wardlaw, D.: Diagnosis of lumbosacral nerve root anomalies by magnetic resonance imaging. J Spinal Disorders 2001; 14: 143-149.

11. Kadish, L.J., Simmons, E.H.: Anomalies of the lumbo- sacral nerve roots. An anatomical investigation and myelographic study. J Bone Joint Surg B 1984; 66: 411-416.

12. Kikuchi, S., Hasue, M., Nishiyama, K., Ito, T.: Anatomic and clinical studies of radicular symptoms. Spine 1984; 9: 23-30.

13. Maiuri, F., Gambardella, A.: Anomalies of the lumbosacral nerve roots. Neurological Research 1989; 11: 130-135.

14. McCormick, C.C.: Developmental asymmetry of roots of the cauda equina at metrizamide myelography: report of seven cases and review of the literature. Clin Radiol 1982; 33: 427-434.

15. Norman, W.J., Johnson, C.: Case report: congenital absence of a pedicle of a lumbar vertebra. Br J Radiol 1973; 46: 631-633.

16. Peyster, R.G., Teplick, J.G., Haskin, M.E.: Computed tomography of lumbosacral conjoined nerve root anomalies. Potential cause of false positive reading for herniated nucleus polposus. Spine 1985; 10: 331-337.

17. Postacchini, F., Urso, S., Ferro, L.: Lumbosacral nerve root anomalies. J Bone Joint Surg A 1982; 64: 721-729.

18. Reynolds, F.C.: The intervertebral disc: surgical technique. Instructional Course Lectures 1954; 11: 121-125.

19. Savas, R., Calli, C., Yunten, N., Alper, H.: Computerized Med Imaging Graph 1998; 22: 77-79.

20. Sener, R.N., Ripeckyi, G.T., Jinkins, J.R.: Agenesis of a lumbar pedicle: MR demonstration. Neuroradiology 1991; 33: 464

21. Sener, R.N, Alper, H., Yunten, N., Yalin, T.: Agenesis of a sacral pedicle and superior facet: CT and MR demonstration. Eur Radiol 1994; 4: 587-588.

22. Torricelli, P., Spina, V., Martinelli, C.: CT diagnosis of lumbosacral conjoined nerve roots. Findings in 19 cases. Neuroradiology 1987; 29: 374- 379.

23. White, J.G. III, Strait, T.A., Binkley, J.R., Hunter, S.E.: Surgical treatment of 63 cases of conjoined nerve roots. J Neurosurg 1982; 56: 114-117.

24. Wortzman, G., Steinhardt, M.I.: Congenitally absent lumbar pedicle: a reappraisal. Radiology 1984; 152: 713-718.

25. Yousefzadeh, D.K., El-Khoury, G.Y., Lupetin, A.R.: Congenital aplastic-hypoplastic lumbar pedicle in infants and young children. Skeletal Radiology 1982; 7: 259-265.

26. Zagnoni, C.: Reperto di un tipo non conosciuto di anastomosi nervosa delle radici spinali. Atti Soc Med Chir Padova 1949; 27: 48-52.

Artico, M.; Carloia, S.; Piacentini, M.; Ferretti, G.; Dazzi, M.; Franchitto, S.; Bronzetti, E.: Conjoined lumbosacral nerve roots: observations on three cases and review of the literature. Neurocirugía 2006; 17: 54-59.

Correspondence: Prof. Marco Artico. Facoltà di Farmacia. Università degli Studi di Roma "La Sapienza", P.le Aldo Moro 5, 00185 Roma. Italy. 